\title{
타이드 원조의 \\ 양허성 감소효과와 시사점
}

정 우 용 / KOICA 조달팀장

\section{I . 머리말}

경제협력개발기구(OECD)의 개발원조위원회 $(\mathrm{DAC})$ 는 공적개발원조 $(\mathrm{ODA})$ 의 정의를 충족시키는 조건의 하나로써 양허성 차관 (Concessional Loan) 의 증여율(Grant Element)을 $25 \%$ 이상으로 설정하 고 있고, 개도국에 대한 전체 $\mathrm{ODA}$ 의 증여율은 $86 \%$ 이상을 권고하고 있다. 이러한 증여율의 기준은 타잉 (Tying) 등과 함께 소위 원조의 질(quality)을 나타내 는 한 가지 지표로 사용되고 있지만 원조의 타이드 (tied) 여부에 관계없이 제시되고 있다. 즉, $\mathrm{DAC}$ 기준 의 양허성은 명목상의 가치로 측정되고 있으며, 양허 성 변화에 영향을 미치는 주어진 지원조건 외의 다른 변수나 상황에 대해서는 별도의 고려를 하고 있지 않 은 바, 특히 타이드시의 실질 증여율이 하락하는 효 과를 간과하고 있다. $\mathrm{DAC}$ 의 양허성 측정 기준은 $10 \%$ 할인율 및 $25 \%$ 증여율 기준의 고정, 양허성 차 관의 즉시지출 가정, 인플레이션 효과 및 환율변동의
미반영 등 여러 가지 문제점을 가지고 있지만 본고에 서는 원조의 수혜자인 수원국의 관점에서 본 타이드 원조가 미치는 양허성 감소 효과를 검토해보고 우리 나라 원조에의 시사점을 살펴보고자 한다.

\section{II. 타이드 원조의 효과}

\section{DAC의 양허성 목표}

양허성(Concessionality)은 원조의 질을 표시하는 지표 중 가장 많이 인용되는 기준의 하나로, 소위 증 여율로써 측정된다. 증여율(GE)은 차관의 액면가에 서 앞으로 상환하게 될 원리금의 합계를 $10 \%$ 로 할인 한 현재가를 감하여 계산한다. 즉,

$$
G E=F-\sum_{n=1}^{N} \frac{R^{n}}{(1+r)^{n}}
$$

가 된다. 여기서 $\mathrm{F}$ 는 양허성 차관의 액면가, $\mathrm{Rn}$ 은 $\mathrm{n}$ 
년 동안 상환하게 될 원리금의 합계, $\mathrm{N}$ 은 차관의 상 환기간, 그리고 $r$ 은 할인율을 나타낸다. 원조가 양허 성 차관의 형태를 가질 때 무상의 요소가 보통 포함 된다. 이런 무상의 요소는 상업성 차관과 구별되는 특성 중의 하나이다. 순수 무상원조는 증여율이 $100 \%$ 이고 따라서 수원국의 입장에서는 상환의 의무 는 없다. 그러나 예컨대 $10 \%$ 의 이자율을 가진 상업차 관은 $10 \%$ 의 할인율 가정 때문에 상환기간에 관계없 이 증여율은 'O’ 이 된다.

수원국의 입장에서는 증여율이 높을수록 원조의 질이 높다. 원조제공에 있어서 양허성의 조건은 수 원국의 관점에서는 채무상환 부담을 완화해주고 공 여국의 입장에서는 공여국들의 부담을 판단하는 기 준-따라서 순위를 결정-을 제시해준다. 즉 양허성 차관이 원조로 인정되기 위해서는 적어도 $25 \%$ 이상 의 증여율이 필요한데 높은 양허성 제공은 그렇지 않은 조건의 차관보다 원조제공에 따르는 부담이 크 지만, 수원국에게는 그만큼 질 높은 원조가 제공되 게 된다. DAC는 양허성의 조건과 기준을 1972 년에 처음으로 권고하였는데 모든 개도국에 대한 적어도 평균 84\%의 증여율을 목표로 삼았고 1978년에는 전체 $\mathrm{ODA}$ 에 대한 증여율을 $86 \%$ 이상으로 상향 조 정하였다. 또한 최빈국에 대한 증여율은 연평균 $90 \%$ 또는 3 년 평균 $86 \%$ 이상을 준수할 것을 권고 하고 있다.

\section{2. 타이드 원조의 비용}

원조의 타이드 역시 원조의 질을 나타내는 대표적 인 지표 중의 하나이다. 타잉(Tying)은 타이드되지 않은 지원에 비하여 원조의 가치를 감소시킨다. 수원 국의 관점에서 볼 때는 타잉은 부정적인 요소이다. 특히 구매타잉(Procurement Tying)은 수원국의 비 용을 증가시키고 원조수입의 실질가치를 감소시킨 다. 왜냐하면 수원국의 자원선택의 폭을 좁히고, 비 경쟁적 입찰을 통해서 수원국에 더 높은 비용을 야기 함으로써 구매가격을 높이기 때문이다. 높아진 구매 가격은 양허성을 또한 상쇄시키게 된다. 공여국의 입 장에서 볼 때 구매 타잉은 높은 가격, 비경쟁산업을 유지시키는 데 일조하고 무역의 보호주의 효과와 유 사한 정책주도형 시장실패를 가져다준다. 공여국이 타이드원조를 선호하게 되는 주요 이유로는 흔히 국 제수지 지출 억제와 고용의 창출효과를 든다.

그러나 모슬리(Mosley, 1987)와 모리씨(Morrissey, 1990)의 연구에 의하면 타이드 원조가 수출과 고용 촉진에 미치는 실제 영향은 일반적으로 믿는 것과는 달리 상당히 미약하며 또한 양자간 타이드 원조로부 터 얻게 되는 공여국의 경제적 이익은 다자간 언타이 드 원조로부터 얻는 것보다 오히려 약하다고 분석하 고 있다.1) 타이드 원조를 통해 보호받게 되는 비경쟁 산업의 경우 국제수지 및 고용에 대한 단기적인 이익 을 발생할 수 있지만 이미 수출을 하고 있는 경쟁산

1) 모리씨(1990)는 투입-산출효과 분석을 이용하여 영국경제에의 다자간 및 양자간 타이드원조의 영향을 측정하였다. 그 결과, 100만 파운드의 다자간 원조 는 180 만 파운드의 수출, 180 만 파운드의 총 생산, 그리고 연간 59 명의 고용을 창출하지만, 100 만 파운드의 양자간 타이드 원조는 단지 66 만 파운드의 수출, 110만 파운드의 총 생산, 그리고 연간 36명의 고용창출에 그치고 있다고 분석하였다. 
업은 여하튼 원조 프로젝트를 수주할 것이며 따라서 국제수지와 고용에 대한 타잉의 긍정적인 효과는 원 조 프로젝트로부터 기대되는 발주의 크기보다는 중 요하지 않을 것이다.

또한 슈혼헤르와 보글러 루드윅(Schonherr and Vogler-Ludwig, 2002)의 연구에 따르면, 언타이드 원조의 경제적 효과는 수원국에서 선의를 축적(a stock of goodwill)시켜 향후 수출을 통해서 공여국 에 이익을 주는 것이라고 분석하고 있다. 그들은 공 여국의 수출에 대한 원조의 영향을 측정한 결과 공여 국의 수출에 대한 타이드 원조의 긍정적인 효과는 과 대평가되어온 반면, 언타이드 원조의 이익은 과소평 가되었다고 한다. 즉, 언타이드 원조가 보통 우리가 믿는 것처럼 과도한 비용부담을 발생시키지는 않는 다는 것이다.

구매 타잉은 개도국의 경제를 장기적으로 심각하 게 왜곡시킬 수 있다. 타이드 원조로 구매된 재화는 보통 국제경쟁시장에서보다 가격이 높다. 타이드 원 조가 수원국에 가져다주는 가격상승의 범위는 $12 \%$ (Haq, 1967), 20\% 내지 25\% (Bhagwati, 1970), 10 내지 20\% (Riddell, 1983), 그리고 74\% (Yassin, 1991)등 다양한데 보다 최근의 젭마(Jepma, 1993)의 연구는 타이드 원조 제공시 그 명목 가치에 비해 실 질가치가 $15 \%$ 내지 $30 \%$ 가량 감소함을 측정하였다. 그러나 타이드 원조가 가격상승과 관련해서는 반드 시 나쁜 것만은 아니라는 데 유의할 필요가 있다. 타 이드 원조가 적정한 가격의 재화를 공급해 줄 수도 있기 때문이다. 예를 들면 우리나라가 특정 분야나 서비스에서 비교우위를 가진다면 타이드 원조의 초
과비용은 상대적으로 낮을 수도 있다.

타이드 원조의 가격효과 외에 다른 나쁜 영향을 주는 것은 공여국이 선호하는 혼합신용과 같은 것을 통한 수출촉진으로부터 오는 본연의 왜곡이다. 이런 점에서 $\mathrm{OECD}(1985)$ 는 다음과 같이 타이드 원조가 개도국 경제에 주는 왜곡을 지적하였다. 첫째, 수입 품을 포함하는 프로젝트에 대한 선호, 둘째, 상업적 으로 관심이 있는 개도국에 부여하는 특혜 지위, 셋 째, 상업적으로 관심이 있는 프로젝트에 대해 경쟁자 로 보이는 다른 공여국과의 원조조정에 참여 유보, 그리고 다자간 원조를 통한 참여 유보 등이다. 이러 한 왜곡에 대한 영향은 수원국에 제공되는 재화와 서 비스가 과도하게 자본집중적이며, 선진국의 기술에 상당히 종속적인, 그리고 수입지향적인, 따라서 낮은 우선순위에 해당되는 것들이 된다.

\section{DAC의 언타잉 목표}

$\mathrm{DAC}$ 역시 설립초기부터 타잉의 관행을 규제해오 고 있다. 1965년의 DAC의 타잉관련 권고는 원조자 금으로 구매시 제약을 가능한 한 감소하라고 권고하 였고 또한 타이드 원조의 부정적 효과를 감소시킬 수 있는 단계를 제안하였다. 1974 년에는 10 개국의 DAC 회원국이 개도국의 구매에 호혜적인 양자간 개발차 관의 언타잉에 관한 양해각서에 서명하였다. 이러한 부분 언타잉 체제하에서 원조자금을 사용한 개도국 으로부터의 구매가 가능해졌다. 더욱이 1986년에 채 택된 구매에 관한 $\mathrm{DAC}$ 의 지침은 가격상승을 감소시 키는 경쟁적인 입찰과 계약을 장려하였다. 언타잉과 관련한 가장 최근의 논의는 최빈국(LLDCs)에 대한 
언타잉 원조제공에 관한 것이다. DAC는 2001년부터 회원국들에게 최빈국에 대해서는 언타잉 원조를 권 고하고 있다.

\section{4. 타이드 원조의 양허성 감소효과}

원조의 타이드화는 수원국의 입장에서는 공여국 의 재화나 서비스의 가격을 상승시킴으로써 명목 양 허성의 실질가치를 감소시킨다. 즉 명목 양허성 차관 의 액면가치는 타잉으로 인해 상승된 가격만큼 타이 드 원조의 양허성을 조정하여 감소된다.

일찍이 화이트(White, 1974)는 이러한 양허성 감 소효과를 공여국 물가지수(Donor Price Index: DPI) 를 사용하여 설명하였다. 예를 들면 수원국이 국제 경쟁가격으로 100 불 가치의 재화와 용역을 공여국의 타이드된 가격인 150 불 상당으로 제공받을 때 $\mathrm{DPI}$ 는 1.5 가 된다. 실질 증여율(Aid Equivalent: AE)은 DPI 를 반영하여 계산되는데 차관의 액면가는 DPI만큼 축소하게 된다. 즉,

$$
A E=(F / D P I)-\sum_{n=1}^{N} \frac{R_{n}}{(1+r)^{n}}
$$

\section{가 된다.}

모리씨와 화이트(Morrissey and White, 1994)도 같은 맥락에서 타이드 원조의 양허성 하락효과를 구 체적으로 측정하였다. 타이드 원조의 가격상승효과 를 반영한 조정된 양허성(Adjusted Grant Element: AGE)은 화이트(White, 1972)의 DPI의 역수에 의해 차관의 액면가치가 감소함을 증명하였다. 즉,

$$
A G E=[(P w / P d) \times F]-\sum_{n=1}^{N} \frac{R_{n}}{(1+r)^{n}}
$$

가 된다. 여기서 $\mathrm{Pw}$ 는 프로젝트의 국제가격, $\mathrm{Pd}$ 는 프로젝트의 공여국 가격을 나타낸다. 이 식으로부터 타잉으로 인한 초과비용의 명목 양허성 상쇄효과를 계산할 수 있는데 명목 증여율 (GE)공식을 활용하여 다시 정리하면

$$
\mathrm{GE}=(\mathrm{Pd} / \mathrm{Pw}-1) /(\mathrm{Pd} / \mathrm{Pw})
$$

가 된다.

이 식으로부터 예를 들면, $\mathrm{ODA}$ 차관의 충족조건 인 $25 \%$ 의 증여율 $(\mathrm{GE})$ 을 상쇄하기 위해서는 $33 \%$ 의 초과비용(DPI)이 발생하여야 함을 알 수 있다.

표1은 타잉으로 인한 초과비용이 젭마(Jepma, 1993)가 측정한 $15 \%$ 내지 $30 \%$ 일 경우를 가정할 때 타잉이 OECD/DAC 회원국 원조의 실질가치를 명 목가치에 비해 약 $1 \%$ 2\%만큼 감소시키고 있음을 보여준다. 2003년 기준으로 양자간 명목원조 총액 인 313억불이 실질적으로 310 억불과 306억불로 감 소되고 평균 양허성은 $98.4 \%$ 에서 각각 $97.4 \%$ 와 $96.3 \%$ 로 감소된다. 타이드 비중이 평균 $14.6 \%$ 로 그다지 크지 않기 때문에 명목가치가 크게 감소되 지 않았지만 개별 국가의 경우를 살펴보면 타이드 원조의 비중이 높을수록 오스트리아, 캐나다, 스페 인 등의 원조가 보여주듯이 원조의 실질가치는 큰 폭으로 감소하게 된다. 타이드 원조 비중이 가장 큰 오스트리아의 경우는 양허성이 각각 $7.3 \%$ 와 $14.7 \%$ 
〈표 1. 타이드 원조의 양허성 감소효과 (2003)〉

(단위: 백만불)

\begin{tabular}{|c|c|c|c|c|c|c|c|c|}
\hline \multirow{2}{*}{ 국가 1) } & \multirow{2}{*}{$\begin{array}{l}\text { 양자간 } \\
\text { ODA }^{2)} \\
\end{array}$} & \multirow{2}{*}{ 증여율(\%) ${ }^{3)}$} & \multirow{2}{*}{$\begin{array}{c}\text { 타이드 } \\
\text { ODA(\%) }\end{array}$} & \multirow{2}{*}{$\begin{array}{c}\text { 타이드 } \\
\text { ODA }\end{array}$} & \multicolumn{2}{|c|}{ 실질 ODA } & \multicolumn{2}{|c|}{ 실질증여율 (\%) } \\
\hline & & & & & $15 \%$ & $30 \%$ & $15 \%$ & $30 \%$ \\
\hline 호주 & 330.0 & 100.0 & 32.8 & 108.0 & 313.8 & 297.6 & 95.1 & 90.2 \\
\hline 오스트리아 & 133.0 & 100.0 & 48.6 & 65.0 & 123.3 & 113.5 & 92.7 & 85.3 \\
\hline 벨기에 & $1,162.0$ & 99.5 & 0.9 & 10.0 & $1,160.5$ & $1,159.0$ & 99.4 & 99.2 \\
\hline 카나다 & $1,049.0$ & 100.0 & 47.4 & 497.0 & 974.5 & 899.9 & 92.9 & 85.8 \\
\hline 덴마크 & 650.0 & 100.0 & 28.5 & 185.0 & 622.3 & 594.5 & 95.7 & 91.5 \\
\hline 핀란드 & 224.0 & 100.0 & 14.2 & 32.0 & 219.2 & 214.4 & 97.9 & 95.7 \\
\hline 프랑스 & $5,013.0$ & 95.1 & 3.1 & 153.0 & $4,990.1$ & $4,967.1$ & 94.6 & 94.2 \\
\hline 독일 & $3,031.0$ & 97.2 & 5.4 & 163.0 & $3,006.6$ & $2,982.1$ & 96.4 & 95.6 \\
\hline 그리스 & 96.0 & 100.0 & 5.0 & 5.0 & 95.3 & 94.5 & 99.2 & 98.4 \\
\hline 아일랜드 & 316.0 & 100.0 & 0.0 & 0.0 & 316.0 & 316.0 & 100.0 & 100.0 \\
\hline 일본 & $12,634.0$ & 87.5 & 3.4 & 430.0 & $12,569.5$ & $12,505.0$ & 87.0 & 86.5 \\
\hline 뉴질랜드 & 81.0 & 100.0 & 18.6 & 15.0 & 78.8 & 76.5 & 97.2 & 94.4 \\
\hline 노르웨이 & $1,304.0$ & 100.0 & 0.1 & 2.0 & $1,303.7$ & $1,303.4$ & 100.0 & 100.0 \\
\hline 포르투갈 & 32.0 & 100.0 & 6.3 & 2.0 & 31.7 & 31.4 & 99.1 & 98.1 \\
\hline 스페인 & $1,017.0$ & 92.0 & 44.0 & 447.0 & 950.0 & 882.9 & 85.4 & 78.8 \\
\hline 스웨덴 & $1,811.0$ & 99.9 & 0.0 & 0.0 & $1,811.0$ & $1,811.0$ & 99.9 & 99.9 \\
\hline 스위스 & 666.0 & 100.0 & 3.6 & 24.0 & 662.4 & 658.8 & 99.5 & 98.9 \\
\hline 영국 & $1,729.0$ & 100.0 & 0.0 & 0.0 & $1,729.0$ & $1,729.0$ & 100.0 & 100.0 \\
\hline DAC Total & $31,278.0$ & 98.4 & 6.8 & $2,138.0$ & $30,957.3$ & $30,636.6$ & 97.4 & 96.3 \\
\hline 한국 & 266.6 & 86.9 & 80.6 & 214.8 & 234.4 & 202.2 & 74.8 & 62.7 \\
\hline
\end{tabular}

자료: OECD (2004), 정창호(2005)

주: 1)타이드원조 실적이 기록된 국가만 표기함. 2)기술협력과 행정비는 제외한 승인액 기준임. 3)총 ODA 기준임.

만큼 크게 감소하였다. 한편, $\mathrm{DAC}$ 회원국 중 명목 증 여율 최저치의 실적을 보이고 있는 일본2)은 $\mathrm{DAC}$ 평 균(14.6\%)보다 횔씬 낮은 타잉 비율(3.4\%) 때문에 명 목 양허성과 실질 양허성간 차이가 $\mathrm{DAC}$ 평균의 차이 보다도 적다.

\section{III. 우리나라 타이드 원조의 실질 양허성}

우리나라 양자간 원조는 2003년 승인액 기준으로 타이드 비율이 $80.6 \%$ 를 차지하고 있기 때문에 실질 양허성은 큰 폭으로 하락하게 된다. 표1에서 보듯 우 리나라의 양자간 명목ODA는 267백만불에 이르나

2) 명목 증여율이 최저치를 기록하고 있는 주요 이유는 전체 ODA에서 차지하는 무상비율이 저조하기 때문이다. 2002-2003년 평균 양자간 원조의 무상비 율은 46.8\%(DAC평균 86.1\%), 전체 원조의 무상비율은 $56.2 \%(\mathrm{DAC}$ 평균 $89.6 \%$ )로서 각각 DAC회원국 중 최저치를 기록하고 있다. 
$15 \%$ 와 $30 \%$ 의 타이드된 초과비용을 가정하면 수원 국에 제공되는 $\mathrm{ODA}$ 의 실질가치는 234 백만불과 202 백만불로 감소하게 된다. 또한 증여율 기준으로 보면 명목 증여율 $86.9 \%$ 에서 각각 실질 증여율인 $74.8 \%$ 및 $62.7 \%$ 로 하락하여 $12.1 \%$ 내지 $24.2 \%$ 감소 하게 된다. 그러나 명목 증여율은 $86 \%$ 의 기준을 상 회함으로써 일단 $\mathrm{DAC}$ 의 권고수준을 충족하고 있다.

우리나라 $\mathrm{EDCF}$ 차관의 공여조건이 최근 많이 개 선되어 $\mathrm{OECD} / \mathrm{DAC}$ 회원국과 증여율에 있어서 그다 지 많은 차이가 나지 않지만 ${ }^{3)} \mathrm{ODA}$ 전체 증여율로 볼 때 유상원조의 증여율보다는 크게 저조한 실정이다. 표1에서 보듯이 $\mathrm{DAC}$ 회원국이 매우 높은 양허성을 가지고 있기 때문에 $11.5 \%(98.4 \%$ 86.9\%)의 많은 차 이가 발생한다. 이러한 차이가 발생하는 큰 이유 중 의 하나는 $\mathrm{DAC}$ 의 높은 무상원조 비율 때문이며 4 , 이 러한 $\mathrm{DAC}$ 의 무상원조 비율은 해마다 높아지고 있는 추세이다. 2002 2003년도 승인액 기준으로 DAC의 양자간 무상비율은 평균 $86.1 \%$ 에 이르고 있으나5) 우 리나라 양자간 무상비율은 $36.1 \%$ 에 그치고 있어 $50 \%$ 의 격차가 발생하고 있다. 이는 DAC의 양자간 무상비율 최저치인 일본의 $46.8 \%$ 에도 $10 \%$ 이상 차 이가 나는 저조한 실적이다. 원래 $30 \%$ 이하 수준이 었던 우리나라 원조의 양자간 무상비율은(2001년 $30.3 \%, 2002$ 년 26.2\%) 그나마 2003년에 아프가니
스탄과 이라크에 대한 대규모 무상재건복구비용이 산정되어 $46.0 \%$ 로 크게 증가한 것이다.

통상적으로 개발 자금이 부족한 개도국의 인프라 건설 등에 무상보다는 규모가 큰 양허성 차관의 개도 국 경제개발 지원이라는 긍정적인 역할 기대와 그에 따른 공여국 기업 및 물품의 진출(수출) 촉진을 통한 경제적 이익 수취, 그리고 개도국에 차관의 상환부담 때문에 자금의 합리적인 사용을 유도한다는 점 등이 양허성 차관의 공여이유로 주로 거론되어 왔다. 그럼 에도 불구하고 위에서 살펴본 바와 같이 대부분의 $\mathrm{DAC}$ 회원국이 무상원조를 제공하는 추세로 가는 이 유는 첫째, 근래에 들어 국제개발협력의 핵심 이슈로 등장하고 있는 공여국과 개도국의 파트너십 정립 및 개도국의 오너쉽(ownership) 고양 등을 위해 DAC 에서 지속적으로 심사(Peer Review)하고 있는 타잉 축소와 양허성 개선 권고에 따라 특히 양허성 개선을 위해서는 불가불 유상원조의 비중을 축소하여야 한 다는 점, 둘째, 매우 좋은 조건으로 대부되고 있는 양 허성 차관도 원리금이 상환된다는 사실 이외에는 공 여국에게는 무상원조와 실질적으로 다를 바 없는 재 정적 부담이라는 점(), 셋째, 유상보다는 무상원조를 제공함으로써 인도주의적 측면이 부각되는 대내외 홍보효과와 그로 인한 국가 브랜드 및 이미지 제고, 넷째, 악화되고 있는 개도국의 부채상환 능력에 대한

3) 2003 년 기준 우리나라의 EDCF차관의 명목 증여율은 $66.4 \%$ 로서 동년 OECD/DAC회원국의 유상원조 증여율 평균인 $68.0 \%$ 에 조금 못 미치고 있다. 4) 전체 양허성이 모든 무상 및 유상원조 증여율의 가중평균치로 계산되기 때문이다.

5) 2000 2001년 기준으로는 양자간 무상비율은 평균 $77.8 \%$ 이다.

6) 공여국의 경제상황 및 지원조건에 따라서는 오히려 차관이 무상증여보다 더 큰 부담이 될 수도 있다. 
대응 ${ }^{7}$, 그리고 마지막으로 양허성 차관의 타이드 원 조 사용제약이 증대되는 추세로 특히 OECD는 1992 년에 소위 헬싱키패키지라고 불리는 공적수출신용 협약(Arrangement on Officially Supported Export Credits)을 제정하여 중소득국 이상의 국가 에 대한 타이드 원조 금지와 상업적으로 채산성이 있 는 프로젝트의 타이드 원조 규제를 더욱 강화하는 등 유상원조의 입지가 더욱 좁아지고 있는 점 등이 복합 적으로 작용하고 있는 것으로 판단된다.

\section{IV. 결론}

타이드 원조는 양허성을 상쇄시켜 원조의 실질가 치를 감소시키기 때문에 수원국의 관점에서 볼 때 원 조의 질이 저하된다. 우리나라 원조의 명목 양허성은 평균 87\%로서 $\mathrm{DAC}$ 평균(98\%)에 비해 낮은 수준이 나, 타잉의 정도를 반영할 때는 $80 \%$ 이상의 타이드 원조의 높은 비율과 그로 인한 가격상승효과 때문에 실질적으로 더욱 낮아지게 된다. 그 결과 명목 증여 율은 $12.1 \% \sim 23.2 \%$ 정도 실질가치가 감소하게 된다. 반면, DAC 회원국의 실질 양허성은 낮은 타잉비율 (14.6\%) 때문에 실질 하락폭은 평균적으로 1 2\%에 그치고 있다.

명목상 양허성의 수준을 제고하기 위해서는 먼저 $\mathrm{EDCF}$ 차관 지원 조건의 개선, 즉 이자율 하락, 거치
기간 및 상환기간 연장 등이 필요하나 $\mathrm{EDCF}$ 의 증여 율은 DAC회원국과 비교해볼 때 이미 상당히 개선되 었으므로 전체 양허성 수준에서는 무엇보다도 우선 무상부분의 확대가 필요하다. 특히 DAC 회원국 양 자간 무상비율의 평균수준(86.1\%) 도달을 위해서는 우리나라도 무상원조비율을 $50 \%$ 이상 높이는 획기 적인 증대가 필요하다. 무상 비율이 $\mathrm{DAC}$ 회원국 중 최저치인 일본의 경우 $\mathrm{DAC}$ 평균보다 매우 높은 언타 잉 비율에도 불구하고 전체 양허성 실적에 영향을 미 쳐 역시 DAC 최저치를 기록하고 있다. 한때 세계 제 1 위의 원조대국이었음에도 불구하고 막대한 엔차관 을 이용한 일본원조가 경제적 이익추구에 비중을 둔 나머지 원조효과가 희석되고 또 국제사회에서 그다 지 좋은 평판을 얻지 못한 점은 우리나라 원조가 앞 으로 타산지석으로 삼을 필요가 있다.

우리나라가 $\mathrm{DAC}$ 에 가입하기 전 사전 정책검토 (Pre Peer Review)에 대비하고 가입 이후라도 DAC 의 지원조건 심사나 실적 순위평가 등을 고려할 때, $\mathrm{ODA}$ 의 양적 증대와 함께 양허성 제고와 특히 언타 잉 비율을 증가시킴으로써 원조의 질을 개선할 필요 가 있다. 언타이드 원조가 보통 우리가 믿는 것처럼 과대한 비용 부담을 발생시키지 않는다는 선행 연구 결과도 있다. 우리 기업의 재화와 용역의 국제경쟁력 이 날로 높아져가고 있으므로 우리 경제에 미치는 타 잉의 효과에 대한 실증적 분석과 아울러 타잉에 대한 전반적인 원조정책의 재점검이 필요한 시점이다.

7) 최근(2005. 6.) 선진국 G8 재무장관들은 아프리카, 중남미 대륙 18 개중 채무 빈곤국(HIPCs)이 IMF가 가동하는 HIPCs지원노력과 함께 개도국의 채무 불 이행이 국제사회의 주요 관심사로 떠오르고 있다. 


\section{참고자료}

Bhagwati, J. (1970) Amount and Sharing of Aid, Washington DC.: Overseas Development Council.

EDCF (2004) EDCF Annual Report, Seoul: The Export-Import Bank of Korea.

Haq, M. (1967), 'Tied Credits: a quantitative analysis', in J.H.Alder (ed) Capital Movements and Economic Development, London: Macmilan.

Jepma, C. (1993) 'OECD-Wide Untying', Paper presented at the EADI VII General Conference, Berlin, 15-18 September.

Morrissey, O. (1990) 'The Impact of Multilateral and Tied Bilateral Aid on the UK Economy', Journal of International Development, 12(1): 208-226.

Morrissey, O. and White, H. (1996) 'Evaluating the Concessionality of Tied Aid', The Manchester School, LXIV(1): 208-226.

Mosley, P. (1987) Overseas Aid, Brighton: Wheatsheaf Books.

OECD $(1985,2004)$ Development Co-operation, Paris: OECD.

Riddell, R. (1987) Foreign Aid Reconsidered, London: James Currey Ltd.

Schonherr, S. and Vogler-Ludwig, K. (2002) 'Foreign Aid and Donor Export Performance: The Case of Germany, in B, Arvin (ed) New Perspectives on Foreign Aid and Economic Development, Westport: Praeger.

White, J. (1974) The Politics of Foreign Aid, London: The Bodley Head.

Yassin, I. (1991) 'Aid-tying and the Real Value of Foreign Assistance: The Case of the Sudan', The Pakistan Development Review, 30(2): 189-206.

정창호(2005) 'OECD의 타이드 원조 규제가 우리나라 ODA에 미치는 영향', 대외경제전문가풀 ODA연구회 주제발표 